\title{
Cost-minimization analysis of degludec/liraglutide versus glargine/aspart: economic implications of the DUAL VII study outcomes
}

This article was published in the following Dove Press journal:

ClinicoEconomics and Outcomes Research

\section{Enrico Torre' \\ Giacomo Matteo Bruno ${ }^{2}$ \\ Sergio Di Matteo² \\ Chiara Martinotti ${ }^{2}$ \\ Martina Oselin² \\ Maria Chiara Valentino ${ }^{2}$ \\ Alessio Parodi ${ }^{3}$ \\ Luigi Carlo Bottaro ${ }^{4}$ \\ Giorgio Lorenzo Colombo 5}

'Endocrinology, Diabetology and Metabolic Diseases Unit, ASL3, Genoa, Italy; ${ }^{2}$ S.A.V.E. Studi Analisi Valutazioni

Economiche S.r.l., Health Economics \& Outcomes Research, Milan, Italy;

${ }^{3}$ General Direction International

Evangelic Hospital, Genoa, Italy;

${ }^{4}$ General Direction, ASL3, Genoa, Italy; ${ }^{5}$ Department of Drug Sciences, University of Pavia, Pavia, Italy
Correspondence: Giorgio Lorenzo

Colombo

Department of Drug Sciences, University of Pavia, c/o S.A.V.E. Via Gaetano Previati

74 , Milano 20149, Italy

Tel +390248519230

Email giorgio.colombo@unipv.it
Background: Diabetes represents a relevant public health problem worldwide due to its increasing prevalence and socioeconomic burden. There is no doubt that tight glycemic control reduces the development of diabetic complications such as the long-term costs related to the disease. The aim of our model was to calculate total direct costs associated with the two treatments considered in DUAL VII study, and hence evaluate the potential economic benefits for the National Health System (NHS) deriving from the use of insulin degludec plus liraglutide (IDegLira) in a once-daily fixed combination.

Materials and methods: We applied the cost-minimization technique adopting the NHS point of view to the DUAL VII trial outcomes. In the model, developed in Microsoft Excel ${ }^{\circledR}$, we calculated and compared annual costs per patient of the two therapeutic options for type 2 diabetes (T2D) patients not achieving glycemic control on basal insulin and metformin described in the trial, including costs of therapy management and side effects, both negative and positive. Annual treatment costs were calculated based on IDegLira and basal bolus end-of-trial doses resulting in a 1:2 ratio ( $40.4 \mathrm{U}$ vs $84.1 \mathrm{U}$ ). Therefore, maintaining the IDegLira/basal bolus at $1: 2$ dose ratio, we calculated the correlation between the dose reduction and costs compared to DUAL VII doses base case scenario.

Results: Total treatment costs were obtained by adding annual cost of drug, needles, glycemic self-monitoring, hypoglycemic events, and effect on consumption of other drugs. Total annual costs of IDegLira combination resulted in $€ 434$ higher than basal bolus in DUAL VII base case ( $40.4 \mathrm{U})$; the two treatments reported equal costs at $34 \%$ dose reduction $(26.7 \mathrm{U})$, while below this value IDegLira treatment became less expensive, with about $€ 215$ gain at $50 \%$ dose reduction (20.2 U). It is also important to notice that above the break-even point, until an IDegLira dose of $30 \mathrm{U}$, the cost difference is negligible in view of the clinical benefit provided by the fixed combination highlighted in DUAL VII trial.

Conclusion: Adding the significant clinical findings derived from DUAL VII trial to our economic evaluation, IDegLira seems to offer an important alternative to basal-bolus therapy.

Keywords: diabetes, cost minimization, IDegLira, basal-bolus therapy

\section{Introduction}

Diabetes represents a relevant public health problem worldwide due to its increasing prevalence and socioeconomic burden. In Italy, $>3.2$ million people suffer from diabetes, which is $5.3 \%$ of the total population. ${ }^{1}$ Patients with suboptimal metabolic control are at risk of developing chronic and acute microvascular and macrovascular complications as well as severe hypoglycemia, affecting patients' survival, quality of life, and costs. There is no doubt that tight glycemic control reduces the development of diabetic complications 
such as the long-term costs related to the disease. ${ }^{2,3,4}$ On the other hand, especially in insulin-treated type 2 diabetes (T2D) patients, tight glycemic control is often neglected in order to avoid treatment-related hypoglycemia. ${ }^{5}$ GLP1 agonists were demonstrated to be as effective as sulfonylureas in lowering glycemic levels, exposing patients to a remarkably reduced hypoglycemic risk. ${ }^{6}$ Moreover, the association of GLP1 agonist with basal insulin analogue represents a valid alternative to a basal-bolus scheme, and for the expected additional effect on body weight. ${ }^{7,8}$ Focusing on insulin-treated T2D patients, the recent publication of the DUAL V randomized clinical trial demonstrated that an insulin degludec/liraglutide fixed ratio (IDegLira) is non-inferior to continued titration of insulin glargine in patients with uncontrolled T2D treated with insulin glargine and metformin. ${ }^{9}$ Primary outcome was represented by the non-inferiority in change of $\mathrm{HbAlc}$ levels, while secondary end points were tested for statistical superiority of $\mathrm{HbAlc}$ levels, with an estimated difference of $-0.59 \%(p<0.001)$ in body weight change $(-3.20 \mathrm{~kg}, p<0.001)$ and rate of confirmed hypoglycemic episodes (estimated rate ratio $0.43, p<0.001$ ), all in favor of IDegLira group. However, even if these outcomes could suffice to convince diabetologists, it would not be enough for public health policymakers. Costs of diabetes treatment represent an ever-growing problem, ${ }^{10}$ so that it may not be easy to accept new therapies when this means a further increase in costs, even if these drugs demonstrate to grant an improvement in patient's quality of life. Hence, it follows the need to carry out cost analysis which compares costs of treatment with new drugs versus traditional therapies. For this purpose, the DUAL V study does not fit perfectly. Despite a significant decrease in $\mathrm{HbA} 1 \mathrm{c}$ levels, body weight, and hypoglycemic rate, only the last parameter can be easily inputted in an economic model which considers quantifiable costs, both direct and indirect. The objective difficulty to evaluate gains in metabolic control and weight without performing a qualityadjusted live years (QALY) analysis hinders the development of a convincing model for decision makers. ${ }^{11}$ Therefore, we have to limit our analysis to a comparison of only direct treatment costs, and at the very least look at the indirect ones, such as costs from work-related absenteeism, reduced productivity both at work and home, and reduced labor force participation from chronic disability. Direct costs represent the public health decision makers' point of view, while indirect costs express the perspective of the social community. Then, we need to analyze a study in which at least the metabolic target is kept as stable as possible in order to express most of the benefits obtained in economically valuable terms. DUAL VII ${ }^{12}$ logical evolution of DUAL V, is just fit for this purpose.
DUAL VII is a treat-to-target randomized clinical trial; it demonstrated that a fixed ratio of insulin degludec/liraglutide plus metformin is non-inferior to continued titration of the basal-bolus association of insulin glargine (once per day) and insulin aspart ( $\leq 4$ times per day) (IGlar+IAsp) plus metformin, in patients with uncontrolled T2D treated with IGlar and metformin. Over 500 patients (506, randomized in two groups of 252 and 254, respectively) from 12 countries all over the world were recruited and the study lasted for 26 weeks from randomization. Primary end point was non-inferiority change in $\mathrm{HbAlc}$ levels from baseline to the end of treatment; secondary end points were number of treatment-emergent severe or blood glucose-confirmed symptomatic hypoglycemic episodes and change from baseline in body weight during the treatment. The key results indicated that mean $\mathrm{HbAlc}$ decreased from $8.2 \%$ at baseline to $6.7 \%$ at the end of the trial in both arms, thus confirming non-inferiority for IDegLira; a similar proportion of patients achieved $\mathrm{HbAlc}$ targets with IDegLira versus basal-bolus association $(66.0 \%$ vs $67.0 \%$ for $<7 \% ; 49.6 \%$ vs $44.6 \%$ for $\leq 6.5 \%$, respectively). Total insulin dose was lower for IDegLira (40.4 U) versus basal-bolus (84.1 U), as well as the rate of hypoglycemic episodes: 1.07 vs $8.17(p<0.0001)$ episodes/patient-year of exposure (PYE); $87 \%$ overall reduction in severe or blood glucose confirmed symptomatic hypoglycemic events, and IDegLira vs basal bolus: 0.13 vs $1.66(p<0.0001)$ episodes/PYE confirmed $95 \%$ reduction for nocturnal ones. Moreover, body weight decreased in IDegLira arm and increased in basal-bolus arm $(-0.92$ vs $+2.64 \mathrm{~kg} ; p<0.0001)$; SF-36 (mental component summary) and TRIM-D (total scores) improved more with IDegLira as well, all these outcomes favoring quality of life. Finally, more patients achieved a triple composite end point ( $\mathrm{HbAlc}<7 \%(53 \mathrm{mmol} / \mathrm{mol})$ with no hypoglycemic episodes in the last 12 weeks and no weight gain) with IDegLira versus basal-bolus (IGlar+IAsp) (38.2\% vs 6.4\%).

In summary, from a point of view that considers the treatments costs, achieving the same HbA1c level with IDegLira and basal-bolus grants less hypoglycemic episodes and needs less blood glucose self-monitoring and needle use, as a result of one insulin administration instead of at least four per day, not considering the improvement in quality of life.

\section{Materials and methods}

We applied the cost-minimization technique adopting the National Health System (NHS) point of view to the DUAL VII trial outcomes, and then we extended the perspective to society including the indirect costs related to hypoglycemic event which is the most impactful event among those associated with 
antidiabetic therapy, due to the loss of productivity. DUAL VII treat-to-target randomized clinical trial compared the fixed-ratio combination IDegLira $(100 \mathrm{U} / \mathrm{mL}+3.6 \mathrm{mg} / \mathrm{mL})$ versus basalbolus scheme with insulin analogues glargine and aspart. Both schemes were in continued titration to a target of $\mathrm{HbA} 1 \mathrm{c}<7 \%$, up to 26 weeks. Metformin was present in both arms; therefore, we did not consider it in cost analysis. The aim of our model was to calculate total direct costs associated with the two treatments considered in DUAL VII study, and thereby evaluate the potential economic benefits for the NHS deriving from the use of IDegLira. Afterwards, to define the impact of the two different therapeutic options on total social costs, we also considered the addition of indirect costs closely related to hypoglycemia.

In our analysis we have considered all the resources consumed in providing health care services as well as those used to counteract the possible adverse effects of the therapies used as direct costs. Specifically, direct costs included: drug acquisition costs, cost of needles for injections, cost of strips and lancets for self-monitoring of blood glucose, and costs of hypoglycemic event management. Direct costs represent the point of view of public health decision makers. Indirect costs are instead related to the loss of productivity due to temporary inactivity and/or to a residual limitation in working capacity and family and social costs. The sum of direct and indirect costs expresses the point of view of the social community. Intangible costs, related to the deterioration/improvement in quality of life, those due to weight gain or loss as well as to the fear of hypoglycemia, or to the need of more time to devote to selfmonitoring of blood glucose, were not considered in our model.

\section{Structure of the model}

Our model, developed in Microsoft Excel ${ }^{\circledR} 2016$ (Redmond, WA, USA), compared costs of the two therapeutic options described in the DUAL VII study, including costs of therapy management and side effects, both negative and positive, while costs which do not vary within the two groups, such as costs of metformin and outpatient costs, were not included in the calculation.

To evaluate direct and indirect costs we have considered the following cost items:

- Cost of the drug

- Cost of needle and glycemic self-monitoring

- Direct and indirect costs related to hypoglycemic events

- Costs and savings related to the consumption of other drugs

Our model was developed referring to Italian NHS and data were inputted by reference to the scientific literature, using Italian evaluation of costs whenever possible and referring to internationally acknowledged data when it was not possible otherwise.

Annual treatment costs were calculated based on IDegLira and basal-bolus end-of-trial doses resulting in a 1:2 ratio (40.4 $\mathrm{U}$ and $84.1 \mathrm{U}$, respectively). Due to the ambitious target fixed in the trial, insulin dose at 26 weeks was above the mean dosage commonly used in Italy according to expert opinion and above the mean basal insulin dosage used in addon to existing oral therapies according to clinical practice. ${ }^{13}$ Therefore, maintaining the IDegLira/basal-bolus in 1:2 dose ratio, we developed a sensitivity analysis that considers the impact of dose reduction on costs, to reflect a scenario more similar to that of clinical practice in Italy. We calculated the correlation between the dose reduction and costs compared to DUAL VII doses base case scenario and identified the break-even point between dose reduction and cost of the two therapies in analysis. In addition, we also considered drug distribution costs, to highlight any differences between the two treatments. In definitive, starting from the base scenario considering the direct costs, we included the indirect ones for hypoglycemia and tested the variability of the results at the variation of the dosage, as well as considering the effects of the cost of distribution.

\section{Cost of drugs}

To calculate daily drug costs, we considered data on contents of each pack, doses, administration rate, deducted from Summary of Product Characteristics (SmPCs), and ex-factory prices (with $-5 \%,-5 \%$ mandatory rebates). ${ }^{14}$ We calculated the annual direct cost per patient of each drug using the average dosages described in DUAL VII study. Costs of IDegLira combination were compared to basal-bolus therapy (IGlar+IAsp). For basal-bolus treatment, we adopted a fixed proportion of $50 \%$ between the two insulin types, not so different from real-life data. ${ }^{15}$ Data adopted to calculate costs of pharmacological treatment are shown in Table 1.

\section{Cost of needles and glycemic self-monitoring}

In addition to drug acquisition cost, we considered costs related to needle use and glycemic self-monitoring. Needle use cost was derived based on frequency of administration according to SmPCs and needle unit cost. Since cost of needle differs in our country from region to region, we considered needle unit price adopted in Liguria Region $(€ 0.046),{ }^{16}$ which was chosen as a benchmark. To calculate the total number of needles per day, we assumed it equals the number of daily administrations. 
Table I Pharmacological treatment costs: drug cost

\begin{tabular}{|c|c|c|c|c|c|c|c|}
\hline Drug & $\begin{array}{l}\text { Contents of } \\
\text { the pack }\end{array}$ & $\begin{array}{l}\text { Dose per unit } \\
\text { (ITab; I pen) }\end{array}$ & $\begin{array}{l}\text { Tab/mg/UI } \\
\text { per pack }\end{array}$ & $\begin{array}{l}\text { Tab/mg/UI } \\
\text { per pack }\end{array}$ & $\begin{array}{l}\text { N0 administ. } \\
\text { (die) }\end{array}$ & $\begin{array}{l}\text { Posology } \\
\text { (die) }\end{array}$ & $\begin{array}{l}\text { Ex-factory } \\
\text { price }\end{array}$ \\
\hline Metformin & $60 \mathrm{tab}$ & $1000 \mathrm{mg}$ & 60 & 60 & 2 & 2000 & $€ 3.64$ \\
\hline IDegLira & 5 pens $3 \mathrm{~mL}$ & $300 \mathrm{UI}$ & 1500 & 1500 & 1 & 40.4 & $€ 202.86$ \\
\hline Glargine (Abasaglar) & 5 pens $3 \mathrm{~mL}$ & $300 \mathrm{UI}$ & 1500 & 1500 & I & 40.0 & $€ 36.77$ \\
\hline Aspart & 5 pens $3 \mathrm{~mL}$ & $300 \mathrm{UI}$ & 1500 & 1500 & 3 & 14.7 & $€ 31.72$ \\
\hline IGlar+IAsp & & & & & & 84.1 & \\
\hline
\end{tabular}

Note: Highlighted drugs represent two treatments compared in the analysis.

Abbreviations: IDegLira, insulin degludec plus liraglutide; Tab, tablet; administ., administration; die, daily dose; IGlar, insulin glargine; IAsp, insulin aspart.

To evaluate the costs of glycemic self-monitoring, we looked at the number of recommended blood glucose tests according to national scientific society (Associazione Medici Diabetologi-Società Italiana di Diabetologia [Association of Diabetes Doctors and the Italian Society of Diabetes]) guidelines, ${ }^{17}$ and at strip and at lancet unit cost. We considered one sample per day for patients treated with IDegLira and 30 samples per week (one per each insulin administration plus two per week at disposal for the management of hypoglycemic events) for patients treated with basal-bolus scheme. ${ }^{17}$ We assumed that cost per blood glucose test includes strip unit cost and lancet unit cost. Such as for needle, strips cost varies in our country with an average price of about $€ 0.55$ per unit. In our model, we adopted the last price suggested by CONSIP (Italian public procurement office), which amounts to $€ 0.35 .{ }^{18}$ We should also consider that, even if prices offered in the latest public tenders are getting lower and lower, new technologies in glycemic monitoring (i.e., continuous monitoring portable devices) are spreading and this will probably bring up average costs again. Then, we considered the cost of blood sampling amounting to $€ 0.0145$ per lancet, according to Liguria tariffs. ${ }^{19}$ Data input on frequency of use and device unit costs adopted are shown in Table 2.

\section{Cost of hypoglycemic events}

A hypoglycemic event was defined as an episode with symptoms of low blood glucose levels during which the patient required assistance from another person.

To estimate costs of hypoglycemia, we did not refer to the incidence of episodes detected by DUAL VII study; because of its treat-to-target up-titration design, we could determine an increase in hypoglycemic events. For this purpose, we applied the ratio detected in the study between the two groups of treatment ( $87 \%$ reduction in severe or blood glucose confirmed symptomatic hypoglycemic events) to the incidence of hypoglycemic events reported in international literature for patients with T2D. ${ }^{20,21}$ We considered only severe and moderate hypoglycemia, not including mild hypoglycemia for their negligible impact on direct costs.
Table 2 Needles and glycemic self-monitoring: frequency and unit cost

\begin{tabular}{lll}
\hline Drug & Daily injections* & Weekly SMBG** \\
\hline Metformin & - & $\mathrm{I}$ \\
IDegLira & $\mathrm{I}$ & 7 \\
Glargine (Abasaglar) & $\mathrm{I}$ & 7 \\
Aspart & 3 & 23 \\
IGlar+IAsp & & 30 \\
Device & Unit cost & \\
Needle $^{16}$ & $€ 0.046$ & \\
Strip $^{18}$ & $€ 0.350$ & \\
Lancet $^{19}$ & $€ 0.0145$ &
\end{tabular}

Notes: *Number of needles per day assumed to equal the number of daily administrations; ***weekly SMBG derived from AMD-SID guidelines, ${ }^{17}$ each SMBG assumed inclusive of strip and lancet. Highlighted drugs represent two treatments for branded products were compared in the analysis. "-" indicated no injection required.

Abbreviations: SMBG, self monitoring blood glucose; AMD-SID, Associazione Medici Diabetologi- Società Italiana di Diabetologia [Association of Diabetes Doctors and the Italian Society of Diabetes]; IDegLira, insulin degludec plus liraglutide; IGlar, insulin glargine; IAsp, insulin aspart.

We inputted direct mean costs of severe hypoglycemic events referring to an Italian study, ${ }^{22}$ whereas for moderate and indirect ones we adopted a large Swedish study that reported data about it, already cited earlier. ${ }^{21}$ Data on rates and costs of hypoglycemic events are reported in Table 3.

\section{Costs and gains related to the consumption of other drugs}

Liraglutide reduces systolic blood pressure in patients with T2D, including those receiving concomitant antihypertensive medication. This reduction amounts to an average of 2.7/2.9 mmHg (for drug dosages of 1.2 and $1.8 \mathrm{mg}$, respectively), and results are statistically significant, which is evident within 2 weeks and sustained till 26 weeks. ${ }^{23} \mathrm{In}$ order to economically quantify this benefit, we applied the mean cost of a generic antihypertensive medication (i.e., doxazosine/amlodipine), which amounts to about $€ 0.228$ per day, to the prevalence of hypertension in Italian diabetic population (58.6\%), as reported in our AMD (National Diabetologist Association Annals). ${ }^{24}$ The use of liraglutide allowed a saving of $€ 48.7$ per patient on annual antihyper- 
Table 3 Hypoglycemic events: rates and cost per event

\begin{tabular}{|c|c|c|}
\hline & \multicolumn{2}{|c|}{ Hypoglycemic events rates } \\
\hline & Moderate & Severe \\
\hline \multicolumn{3}{|l|}{$\overline{\text { Drug }}$} \\
\hline Metformin ${ }^{20}$ & $1.00 \%$ & $0.05 \%$ \\
\hline IDegLira $^{12,21}$ & $4.32 \%$ & $1.55 \%$ \\
\hline Glargine (Abasaglar) & $16.5 \%$ & $5.90 \%$ \\
\hline Aspart & $16.5 \%$ & $5.90 \%$ \\
\hline IGlar+|Asp ${ }^{21}$ & $33.00 \%$ & $11.80 \%$ \\
\hline \multicolumn{3}{|c|}{ Hypoglycemic event unit cost } \\
\hline & Moderate & Severe \\
\hline Direct cost per event $t^{21,22}$ & $€ 26.00$ & $€ 1,911.00$ \\
\hline Indirect cost per event ${ }^{21}$ & $€ 37.00$ & $€ I, I 10.60$ \\
\hline
\end{tabular}

Note: Highlighted drugs represent two treatments for branded products were compared in the analysis.

Abbreviations: IDegLira, insulin degludec plus liraglutide; IGlar, insulin glargine; IAsp, insulin aspart.

tensive therapy cost. We did not include in our economic model the demonstrated cardiovascular benefits of treatment with liraglutide since the fixed dosage $(1.8 \mathrm{mg})$ employed in the related study ${ }^{25}$ was greater than the average dosage resulting from DUAL VII.

\section{Additional analysis on drug distribution cost}

In Italy, IDegLira (Xultophy ${ }^{\circledR}$, Novo Nordisk, Bagsværd, Denmark) was approved for reimbursement in October 2017 , and it was listed in the direct distribution formulary (Prontuario della Distribuzione Diretta ospedale - territorio, PHT) including reimbursable pharmaceuticals for patients that require specialized medical visits on a regular basis. ${ }^{26}$ The aim of the formulary (PHT) is to guarantee a balance in pharmaceuticals distribution, in the overall framework of improved health care, and cost-containment. In Italy, direct distribution is performed by regions, and it is carried out by two different channels: distribution of reimbursed medicines to patients by hospitals and "per Conto" distribution (DpC) through the community pharmacy channel. In "per Conto" distribution, reimbursed medicines are purchased by the region and distributed by the pharmacy according to shared stipulations, providing for a fee per pack to the pharmacy. ${ }^{27}$

Currently, IDegLira combination is prescribed by specialized physicians or centers and distributed in conventional regimen, but in future the drug may be dispensed through "per Conto" distribution according to management chosen by each region. Otherwise, degludec insulin and liraglutide, not in combination, are dispensed through "per Conto" distribution. Regarding basal-bolus therapy, glargine insulin provides for "per Conto" distribution, while aspart insulin is dispensed in direct distribution.

To test the economic impact of "per Conto" distribution on final drugs cost, we considered the mean fee per pack established for pharmacist which is variable among regions. We chose five regions, variously placed on national territory, as sample cases: Emilia Romagna (€3.42/pack), Lombardia (€8.44/pack), Liguria (€4.31/pack), Campania (€6.48/pack), and Puglia (€6.35/pack). ${ }^{28}$ Based on units per pack and defined daily dose (DDD), we calculated the number of packs per year and the additional cost due to "per Conto" distribution.

\section{Results}

Based on findings of DUAL VII trial, we calculated and compared annual cost per patient of once-daily fixed-ratio combination IDegLira versus basal-bolus therapy (IGlar+IAsp) for $\mathrm{T} 2 \mathrm{D}$ patients not achieving glycemic control on basal insulin and metformin. Total treatment costs were obtained by adding annual cost of drug, needles, glycemic self-monitoring, hypoglycemic events, and effect on consumption of other drugs, as shown in Table 4.

Considering the end-of-trial doses, total cost of IDegLira combination and basal-bolus therapy was found to be $€ 2,145.75$ and $€ 1,711.88$ respectively (Table 4). IDegLira was more expensive due to the higher drug acquisition cost (€1,995.61 vs $€ 698.76$ ), although, by breaking down the result in the individual items the use of IDegLira showed a positive impact. Liraglutide in place of insulin aspart and once-daily administration of the combination involved lower needle cost ( $€ 16.80$ vs $€ 67.17$ ), lower blood glucose self-monitoring costs ( $€ 132.68$ vs $€ 568.62$ ), and reduction in costs related to hypoglycemia events (direct cost: $€ 30.66$ vs $€ 234.08$; indirect cost: $€ 18.77$ vs $€ 143.26$ ), as well as saving in antihypertensive therapy cost (€48.77) (Table 5).

The end-of-trial doses (84.1 U IGlar plus Aspart and 40.4 U IDegLira) were high in order to meet the target set for the study, although in Italian clinical practice lower doses are commonly used to reach glycemic control in T2D population. Since the final drug cost depends on daily dose, we assessed the correlation between dose reduction and costs (Figure 1).

The point of equivalence in total annual cost was achieved at around a 34\% dose reduction (26.7 U IDegLira; 55.5 U IGlar+IAsp). Under this dose, IDegLira combination increased its economic benefit to reach saving of $€ 214.56$ (€1,147.95 IDegLira vs $€ 1,362.51$ IGlar+IAsp) at a $50 \%$ dose reduction (20.2 U IDegLira; 42.05 U IGlar+IAsp) (Table 6). Above the point of equivalence, IDegLira total annual cost exceeded that of IGlar+IAsp, while maintaining a negligible cost difference until the dose of $30 \mathrm{U}$.

In addition, we also included the drug distribution cost due to "per Conto" channel. Table 7 shows the additional cost per pack reported in the five regions chosen for the analysis. Considering units per pack and DDDs, we obtained 
Table 4 Saving for antihypertensive therapy cost

\begin{tabular}{|c|c|c|c|c|c|c|c|c|}
\hline \multirow[t]{2}{*}{ Drug } & \multirow{2}{*}{$\begin{array}{l}\text { Drug } \\
\text { direct cost }\end{array}$} & \multirow{2}{*}{$\begin{array}{l}\text { Needle } \\
\text { direct cost }\end{array}$} & \multirow{2}{*}{$\begin{array}{l}\text { Monitoring } \\
\text { direct cost }\end{array}$} & \multicolumn{2}{|c|}{ Hypoglycemic events cost } & \multirow{2}{*}{$\begin{array}{l}\text { Antihypertensive } \\
\text { therapy direct } \\
\text { cost }\end{array}$} & \multirow{2}{*}{$\begin{array}{l}\text { Total } \\
\text { annual } \\
\text { direct cost }\end{array}$} & \multirow{2}{*}{$\begin{array}{l}\text { Total } \\
\text { annual } \\
\text { cost }\end{array}$} \\
\hline & & & & direct & indirect & & & \\
\hline Metformin 1000 & $€ 44.31$ & - & $€ 18.95$ & $€ 1.22$ & $€ 0.93$ & 0 & $€ 64.49$ & $€ 65.41$ \\
\hline IDegLira & $€ I, 995.6 I$ & $€ 16.80$ & $€ 132.68$ & $€ 30.66$ & $€ 18.77$ & $€-48.77$ & $€ 2,126.99$ & $€ 2,145.76$ \\
\hline Glargine (Abasaglar) & $€ 358.14$ & $€ 16.80$ & $€ 132.68$ & $€ 117.04$ & $€ 71.63$ & 0 & $€ 624.66$ & $€ 696.29$ \\
\hline Aspart & $€ 340.62$ & $€ 50.37$ & $€ 435.94$ & $€ 117.04$ & $€ 71.63$ & 0 & $€ 943.97$ & $€ 1,015.60$ \\
\hline IGlar+IAsp & $€ 698.76$ & $€ 67.17$ & $€ 568.62$ & $€ 234.08$ & $€ 143.26$ & 0 & $€ I, 568.63$ & $€ 1,711.89$ \\
\hline
\end{tabular}

Notes: Highlighted drugs represent two treatments for branded products were compared in the analysis.

Abbreviations: IDegLira, insulin degludec plus liraglutide; IGlar, insulin glargine; IAsp, insulin aspart.

Table 5 Saving for antihypertensive therapy cost

\begin{tabular}{|c|c|c|c|c|c|c|c|c|}
\hline \multirow[t]{2}{*}{$\overline{\text { Drug }}$} & \multirow{2}{*}{$\begin{array}{l}\text { Daily } \\
\text { insulin } \\
\text { doses (U) }\end{array}$} & \multirow{2}{*}{$\begin{array}{l}\text { Drug } \\
\text { cost }\end{array}$} & \multirow{2}{*}{$\begin{array}{l}\text { Needle } \\
\text { cost }\end{array}$} & \multirow{2}{*}{$\begin{array}{l}\text { Monitoring } \\
\text { cost }\end{array}$} & \multicolumn{2}{|c|}{ Hypoglycemic events cost } & \multirow{2}{*}{$\begin{array}{l}\text { Antihypertensive } \\
\text { therapy cost }\end{array}$} & \multirow{2}{*}{$\begin{array}{l}\text { Total } \\
\text { annual } \\
\text { cost }\end{array}$} \\
\hline & & & & & direct & indirect & & \\
\hline IDegLira & 40.4 & $€ \mathrm{I}, 1995.6 \mathrm{I}$ & $€ 16.80$ & $€ 132.68$ & $€ 30.66$ & $€ 18.77$ & $-€ 48.77$ & $€ 2,145.75$ \\
\hline IGlar+IAsp & 84.1 & $€ 698.76$ & $€ 67.17$ & $€ 568.62$ & $€ 234.08$ & $€ 143.26$ & 0 & $€ I, 7 \mid I .88$ \\
\hline
\end{tabular}

Notes: Highlighted drugs represent two treatments for branded products were compared in the analysis.

Abbreviations: IDegLira, insulin degludec plus liraglutide; IGlar, insulin glargine; IAsp, insulin aspart.

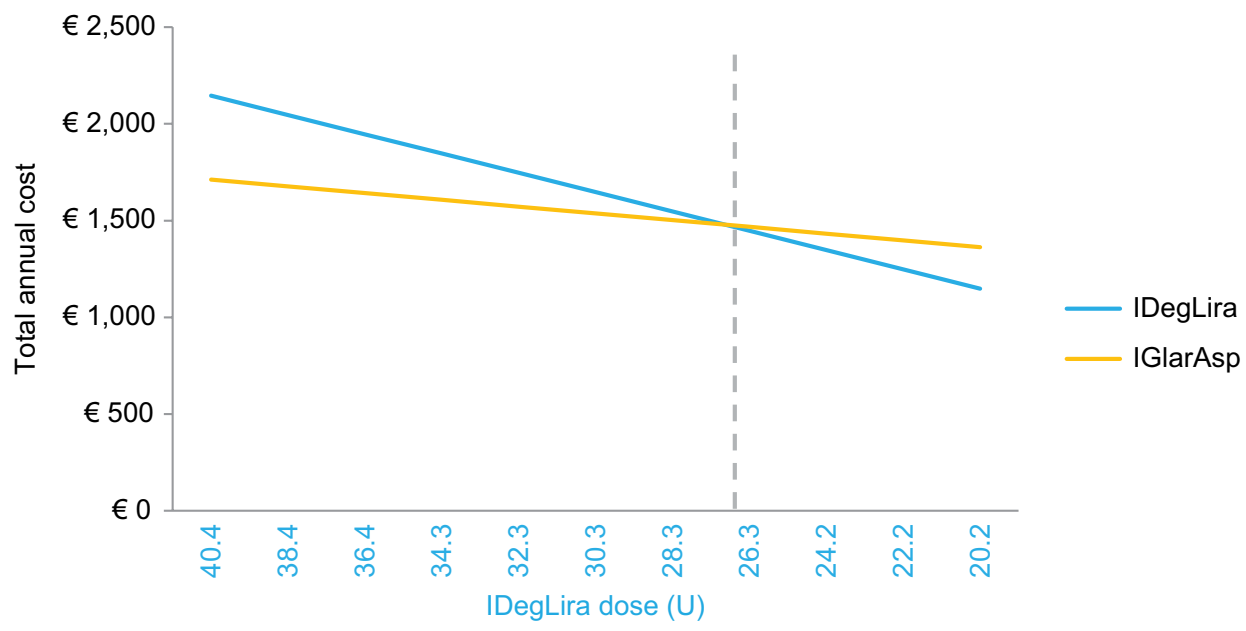

Figure I Correlation between dose and total annual cost.

a consumption of 10 packs per year for each drug in the study. The additional cost per year varied according to the different fee fixed in regions, ranging from $€ 34.20$ in Emilia Romagna to $€ 84.40$ in Lombardia.

By applying the cost due to "per Conto" distribution to results, basal-bolus therapy cost would increase on account of IGlargine "Per Conto" distribution cost to be added to IAspart direct cost. Considering this additional cost, the total cost difference in favour of basal-bolus option reported in the DUAL VII scenario decreased from $€ 433.86$ to $€ 349.46$ in Lombardia case $(€ 2,145.75$ IDegLira vs $€ 1,796.29$ IGlar+IAsp), while in reduced doses scenario IDegLira advantage increased from $€ 214.56$ to $€ 298.96$ ( $€ 1,147.95$ IDegLira vs $€ 1,446.91$ IGlar+IAsp).

\section{Discussion}

The cost-minimization analysis, assuming an equivalent hypoglycemic effect between IDegLira and basal-bolus therapy, allowed the potential benefits in terms of cost reduction related to the fixed combination use to be identified. Although IDegLira acquisition cost was found to be more expensive than IGlar+IAsp, when also other cost items such as needles, blood glucose self-monitoring, and hypoglycemia costs were considered, a significant reduction in costs difference was shown.

Based on DUAL VII head-to-head trial results, we aimed to measure and compare the costs of the two T2D treatments in analysis by adopting the Italian NHS perspective. Clinical and economic outcomes for patients receiving IDegLira and 
Table 6 Saving for antihypertensive therapy cost

\begin{tabular}{|c|c|c|c|c|c|c|c|c|}
\hline \multirow[t]{2}{*}{ Drug } & \multirow{2}{*}{$\begin{array}{l}\text { Daily } \\
\text { insulin } \\
\text { doses (U) }\end{array}$} & \multirow{2}{*}{$\begin{array}{l}\text { Drug } \\
\text { cost }\end{array}$} & \multirow{2}{*}{$\begin{array}{l}\text { Needle } \\
\text { cost }\end{array}$} & \multirow{2}{*}{$\begin{array}{l}\text { Monitoring } \\
\text { cost }\end{array}$} & \multicolumn{2}{|c|}{ Hypoglycemic events cost } & \multirow{2}{*}{$\begin{array}{l}\text { Antihypertensive } \\
\text { therapy cost }\end{array}$} & \multirow{2}{*}{$\begin{array}{l}\text { Total } \\
\text { annual } \\
\text { cost }\end{array}$} \\
\hline & & & & & direct & indirect & & \\
\hline \multicolumn{9}{|c|}{ Reduced doses scenario } \\
\hline IDegLira & 20.2 & $€ 997.81$ & $€ 16.80$ & $€ 132.68$ & $€ 30.66$ & $€ 18.77$ & $-€ 48.77$ & $€ 1,145.95$ \\
\hline IGlar+IAsp & 42.05 & $€ 349.38$ & $€ 67.17$ & $€ 568.62$ & $€ 234.08$ & $€ \mid 43.26$ & 0 & $€|, 362.5|$ \\
\hline
\end{tabular}

Notes: Highlighted drugs represent two treatments for branded products were compared in the analysis.

Abbreviations: IDegLira, insulin degludec plus liraglutide; IGlar, insulin glargine; IAsp, insulin aspart.

Table 7 Costs related to "Per Conto" distribution in five Italian regions

\begin{tabular}{llll}
\hline Region & $\begin{array}{l}\text { Mean distribution } \\
\text { cost per pack }\end{array}$ & $\begin{array}{l}\text { Packs } \\
\text { per year }\end{array}$ & $\begin{array}{l}\text { Annual } \\
\text { cost }\end{array}$ \\
\hline Emilia Romagna & $€ 3.42$ & 10 & $€ 34.20$ \\
Liguria & $€ 4.31$ & 10 & $€ 43.10$ \\
Puglia & $€ 6.35$ & 10 & $€ 63.50$ \\
Campania & $€ 6.48$ & 10 & $€ 64.80$ \\
Lombardia & $€ 8.44$ & 10 & $€ 84.40$ \\
\hline
\end{tabular}

basal-bolus therapy were estimated using data from DUAL VII trial, literature, and ex-factory drug costs (with $-5 \%$, $-5 \%$ mandatory rebates). The analysis considered the effect of IDegLira use mainly on direct costs, representing the point of view of public health decision makers; in addition, indirect costs related to hypoglycemic events were incorporated, while intangible costs were not considered. Total costs of treatments were obtained by adding annual cost of drug, needles, glycemic self-monitoring, hypoglycemic events, and saving from lower consumption of antihypertensive medications. End-of-trial doses (84.1 U IGlar+IAsp and 40.4 U IDegLira) were adopted for the drug cost calculation in DUAL VII scenario, and these reflected the dosage needed to reach the target required by the treat-to-target study design. In the trial, glycemic control target was set at $\mathrm{HbAlc}<7.0 \%$ or $\mathrm{HbA} 1 \mathrm{c} \leq 6.5 \%$, although these values are not always achieved in clinical practice in Italy. ${ }^{24,29}$

In economic evaluation, it is difficult to accurately measure the study variables, and each medication therapy may bring different treatment costs when applied among different populations or medical institutions.

Therefore, to mirror the real-life cost profile, in addition to DUAL VII base case scenario, our analysis was developed assuming lower dose scenario, more representative of Italian setting, and we evaluated the correlation between dose reduction and costs. IDegLira acquisition cost, much higher than IGlar+IAsp, was the main driver of the analysis. Regardless of dose, due to the once-daily administration and clinical benefits, the high IDegLira acquisition cost was partially offset by cost savings because of reduction in rates of hypo- glycemia, needle use, daily self-monitoring of blood glucose, and antihypertensive drug use. In summary, total annual costs of IDegLira combination was observed to be $€ 434$ higher than basal-bolus in DUAL VII base case (40.4 U); the two treatments reported equal costs at $34 \%$ dose reduction $(26.7$ $\mathrm{U})$, while below this value IDegLira treatment became less expensive, with about $€ 215$ gain at $50 \%$ dose reduction $(20.2$ $\mathrm{U})$. Also, it is important to notice that above the break-even point, until an IDegLira dose of $30 \mathrm{U}$, the cost difference is negligible in view of the clinical benefit provided by the fixed combination highlighted in DUAL VII trial. Indeed, hypoglycemia rates and weight gain were significantly lower with IDegLira, and the proportion of patients achieving the triple composite end point $\mathrm{HbA} 1 \mathrm{c}$ value $<7 \%$ without experiencing either hypoglycemia or weight gain was greater with the fixed combination. ${ }^{12}$ Moreover, the once-daily injection allowed lower insulin dose and the reduction of daily self-monitoring of blood glucose. ${ }^{12}$ Decision making based on both clinical and economic evidence is essential as health care providers seek to optimize resource use and care for patients with T2D. Against the backdrop of DUAL VII positive clinical results and the easier administration, it would be interesting to assess the real impact of the treatment on patient's quality of life, and QALY is an important effectiveness measure adopted in the economic evaluation of health outcome. In accordance with cost-minimization technique, we did not include QALY measure in our analysis. Nevertheless, cost-effectiveness analyses from the international literature highlighted that the clinical benefits of IDegLira were achieved at a cost saving from health care payer perspectives considering the impact on quality of life. ${ }^{30-33}$ These studies showed that reduction in hypoglycemia rate and monitoring frequency, besides yielding savings partially off-setting higher drug cost, improves quality of life making IDegLira a cost-effective option. Our analysis takes a conservative approach to capturing economic impact of lower hypoglycemic event rate observed with IDegLira use. Indeed, the positive outcome on hypoglycemia reported in DUAL VII study was applied to general T2D patients' data provided by international literature. ${ }^{20,21}$ Thus, we combined DUAL VII findings with clinical practice data making the 
result more generalizable. Considering the results of DUAL VII the advantages are greater due to the higher dose of insulin administered in the trial, however these results are far from the Italian clinical practice. Moreover, our analysis mainly focused on direct costs, and included indirect costs related to hypoglycemic events, but did not consider intangible costs due to the improvement in quality of life, to weight gain or loss, as well as to the fear of hypoglycemia or to the need of more time to spend self-monitoring blood glucose. Therefore, it is likely that savings with IDegLira would be greater if these costs were also included in the analysis.

Comparing IDegLira with IGlar+IAsp, we also looked at the drug distribution modality, affecting final real cost to be paid by NHS. Taking into account the current protocol for drug distribution, an additional cost for IGlargine was reported due to "per Conto" distribution. This additional cost led to reduction in the total cost difference between treatment options in the DUAL VII dose scenario and to increase the IDegLira advantage in the reduced dose scenario. Even though IDegLira will be distributed "per Conto", its distribution cost will increase while remaining lower than the sum of the distribution cost of two drugs (IGlar plus IAsp or IDeg plus Lira not in combination). This additional analysis aimed to include another significant issue in the comprehensive drug cost calculation and highlight variability among regions and the importance of careful distributive decisions.

To our knowledge, presently, there are no other published studies evaluating the economic impact of IDegLira on reduction in cost from Italian NHS and societal perspective. We have chosen the cost-minimization analysis which, on one hand, represents a method of simple interpretation with respect to other cost-effectiveness analyses, and on the other hand, focusing only on the aspect of costs, excludes the possibility of identifying an indicator of effectiveness, as QALY, that can be included in an incremental cost-effectiveness ratio. Regardless of the limitations of our analysis, it presents the advantage of being based on a head-to-head trial which confirmed IDegLira's efficacy in glycemic control as well as better outcomes on hypoglycemia rates when directly compared with basal-bolus.

The use of clinical trial data, rather than observational real-world data, could also be considered a limitation, due to the stringent nature of clinical trials. To overcome this limit, we combined clinical trial findings with real-world data on insulin doses and hypoglycemia rate to mirror a more realistic scenario and not overestimating the IDegLira benefits.

Results obtained in the reduced dose scenario highlighted the economic benefit related to IDegLira adoption from the Italian NHS perspective, also considering the positive impact of hypoglycemia reduction on society. Nevertheless, the fixed combination cost was found to be more expensive that basalbolus therapy; however, positive effect on hypoglycemia rates, lower need for needles and self-monitoring of blood glucose, as well as antihypertensive therapy cost gain led to minimization in total costs.

\section{Conclusion}

In conclusion, adding the significant clinical findings derived from DUAL VII trial to our economic evaluation, IDegLira seems to offer an important alternative to basal-bolus therapy. It has the potential to address significant unmet needs for T2D patients uncontrolled on basal insulin and requiring treatment intensification; moreover, it reported a good value for money according to Italian NHS, essential in the application of new health technologies into routine clinical practice. Nevertheless, more studies and data from real life and quality of life are needed to understand the comprehensive annual costs of treatments in analysis in the Italian setting and to guide decision making of resource allocation.

\section{Disclosure}

ET has received consultancy and/or speaking fees and research grants from AstraZeneca, Boehringer Ingelheim, Bristol Myers Squibb, Eli Lilly, GlaxoSmithKline, Janssen, Johnson \& Johnson, MSD Italy, Novo Nordisk, Sanofi, and Takeda, over the last 3 years. GLC received research and educational grants from Abbott, Amgen, DOC Generici, Eisai, LeoPharma, Menarini, Merck Sharp and Dohme, Novo Nordisk, Sanofi, and Takeda. The authors report no other conflicts of interest in this work.

\section{References}

1. ISTAT 2017 [National Institute of Statistics]. Diabetes in Italy Years 20002016. Available from: https://www.istat.it/en/files/2017/07/Report_Diabetes_En_def.pdf?title=Diabetes+in+Italy+-+24+Jul+2017+-+Full+ text.pdf. Accessed January 30, 2018.

2. Inzucchi SE, Bergenstal RM, Buse JB, et al. Management of hyperglycemia in type 2 diabetes: a patient-centered approach: position statement of the American Diabetes Association (ADA) and the European Association for the Study of Diabetes (EASD). Diabetes Care. 2012; 35:1364-1379.

3. UK Prospective Diabetes Study (UKPDS) Group. Intensive blood glucose control with sulphonilureas or insulin compared with conventional treatment and risk of complications in patients with type 2 diabetes (UKPDS 33). Lancet. 1998;352:837-853.

4. The Diabetes Control and Complications Trial Research Group. The effect of intensive treatment of diabetes on the development and progression of long-term complications in insulin-dependent diabetes mellitus. N Engl J Med. 1993;329:977-986.

5. Cryer PE. Hypoglycemia is the limiting factor in the management of diabetes. Diabetes Metab Res Rev. 1999; 15:42-46.

6. Nauck M, Frid A, Hermansen K, et al. Long-term efficacy and safety comparison of liraglutide, glimepiride, and placebo, all in combination with metformin in type 2 diabetes: 2 -year result from the LEAD-2 study. Diabetes Obes Metab. 2013;15:204-212. 
7. Anderson SL, Trujillo JM. Basal insulin use with GLP-1 receptor agonists. Diabetes Spectr. 2016;29:152-160.

8. Rosenstock J, Fonseca VA. Advancing basal insulin replacement in type 2 diabetes inadequately controlled with insulin glargine plus oral agents: a comparison of adding albiglutide, a weekly GLP-1 receptor agonist, versus thrice-daily prandial insulin lispro. Diabetes Care. 2014;37(8):2317-2325.

9. Lingvay I, Manghi FP. Effect of insulin glargine up-titration vs insulin degludec/liraglutide on glycated hemoglobin levels in patients with uncontrolled type 2 diabetes the DUAL V randomized clinical trial JAMA. 2016;315(9):898-907.

10. American Diabetes Asscociation (ADA). Economic costs of diabetes in the U.S. in 2012. Diabetes Care. 2013;36:1033-1046.

11. McEwan P, Evans M, Kan H, Bergenheim K. Understanding the interrelationship between improved glycaemic control, hypoglycaemia and weight change within a long-term economic model. Diabetes Obes Metab. 2010;12:431-436.

12. Billings LK, Doshi A, Gouet D, et al. Efficacy and safety of IDegLira versus Basal-Bolus Insulin Therapy in patients with Type 2 diabetes uncontrolled on metformin and basal insulin: the DUAL VII randomized clinical trial. Diabetes Care. 2018;41(5):1009-1016.

13. Khunti K, Caputo S, Damci T, et al. The safety and efficacy of adding once-daily insulin detemir to oral hypoglycaemic agents in patients with type 2 diabetes in a clinical practice setting in 10 countries. Diabetes Obes Metab. 2012;14(12):1129-1136.

14. Tunnel software Pharma Dati. Compendio farmaceutico Farmadati Italia. [Pharma Data Italian database]. Available from: https://www. farmadati.it/. Accessed March 08, 2018. Italian.

15. Abrahamson MJ, Peters A. Intensification of insulin therapy in patients with type 2 diabetes mellitus: an algorithm for basal-bolus therapy. Ann Med. 2012;44:836-846.

16. Regione Liguria, ASL n.3 Determinazione dirigenziale N.1536 23/09/2016. Fornitura di aghi e siringhe per le aziende sanitarie della Regione Liguria [Liguria Region, Local Health Authority N.3. Decision N 1536 23/09/2016. Provision of needles and syringes for Liguria Region Local Health Authorities] Available from: http://delibere.asl3. liguria.it/pdf/determinazioni/2016/2016_1536_2_77_Pubblico.pdf. Accessed March 08, 2018.

17. Associazione Medici Diabetologi (AMD) - Società Italiana di Diabetologia (SID. - Standard italiani per la cura del diabete mellito. 2016. [Doctors Diabetologists Association (AMD) - Italian Society of Diabetology (SID) - Italian standards for the treatment of diabetes mellitus) 2016]. Available from: www.standarditaliani.it. Accessed March 08, 2018. Italian.

18. Consip. Gara a procedura aperta ai sensi del D. Lgs. 163/2006 e s.m.i., per la fornitura di Presidi per l'autocontrollo della glicemia e dei servizi connessi per le Pubbliche Amministrazioni. [Open procedure tender pursuant to Legislative Decree 163/2006 and subsequent amendments, for the supply of products for self-monitoring of blood sugar and services related to Public Administrations]. Available from: www.consip.it/ bandi-di-gara/gare-e-avvisi/gara-presidi-per-lautocontrollo-della-glicemia. Accessed March 08, 2018. Italian.

19. Regione Liguria, ASL n.3. Delibera per la fornitura di dispositivi per la determinazione della glicemia capillare. [Liguria Region, Local Health Authority N.3. Decision for the provision of blood glucose monitoring devices]. Available from: http://delibere.asl3.liguria.it/pdf/ deliberazioni/2016/2016_700_1_77_Pubblico.pdf. Accessed March 08, 2018. Italian.
20. Leese GP, Wang G, Broomhall J, et al. Frequency of severe hypoglycemia requiring emergency treatment in type 1 and type 2 diabetes. Diabetes Care. 2003;26:1176-1180.

21. Jönsson L, Bolinder B, Lundkvist J. Cost of hypoglycemia in patients with type 2 diabetes in Sweden. Value Health. 2006;9:193-198.

22. Veronese G, Marchesini G, Forlani G, et al. Costs associated with emergency care and hospitalization for severe hypoglycaemia. Nutr Metab Cardiovasc Dis. 2016;26:345-351.

23. Fonseca VA, DeVries JH, Henry RR, Donsmark M, Thomsen HF, Plutzky J. Reductions in systolic blood pressure with liraglutide in patients with type 2 diabetes: insights from a patient-level pooled analysis of six randomized clinical trials. $J$ Diabetes Complications. 2014;28(3):399-405.

24. Gruppo Annali AMD. Annali AMD. Valutazione longitudinale 20042011 degli indicatori di qualità dell'assistenza al diabete di tipo 2 nelle regioni italiane. VIII ed. Torino; 2015. [AMD Annals Group. AMD Annals. Long-term evaluation 2004-2011 of the quality indicators of type 2 diabetes care in the Italian regions. VIII ed. turin; 2015]. Available from: http://aemmedi.it/files/ANNALI-AMD/2014/Annali\%20 Regionali\%202014\%20web.pdf. Accessed March 08, 2018. Italian.

25. Marso SP, Daniels GH, Brown-Frandsen K, et al. Liraglutide and cardiovascular outcomes in type 2 diabetes. $N$ Engl J Med. 2016;375: 311-322.

26. Gazzetta Ufficiale. Classificazione del medicinale per uso umano «Xultophy», Serie Generale n.242 del 16-10-2017. [Official Journal. Classification of the medicinal product for human use «Xultophy», General Series n.242 of 16-10-2017]. Italian.

27. AIFA - Italian Medicines Agency. Available from: http://whocc.goeg. at/Literaturliste/Dokumente/CountryInformationPosters/IT_PHIS poster_Rome.pdf

28. De Rosa MM, Garbarini C, Bruno GM. La distribuzione per conto alla luce del nuovo assetto di governance farmaceutica 2017. [Per conto distribution looking to the new governance structure pharmaceutical industry 2017]. Clinico economics italian articles on outcome resources. Vol 12. 2017:127-150. Available from: http://www.clinicoeconomics. eu/articles/flipbook/files/downloads/12_2017_127-150.pdf. Accessed March 08, 2018.

29. Società Italiana di Diabetologia. Il diabete in Italia. A cura di Enzo Bonora e Giorgio Sesti. [Italian Society of Diabetology. Diabetes in Italy. By Enzo Bonora and Giorgio Sesti]. Bologna: Bononia University Press; 2016. Italian.

30. Ericsson A, Lundqvist A. Cost effectiveness of insulin degludec plus liraglutide (IDegLira) in a fixed combination for uncontrolled type 2 diabetes mellitus in Sweden. Appl Health Econ Health Policy. 2017; 15:237-248

31. Hunt B, Glah D, van der Vliet M. Modeling the long-term cost-effectiveness of IDegLira in patients with type 2 diabetes who are failing to meet glycemic targets on basal insulin alone in the Netherlands. Diabetes Ther. 2017;8:753-765.

32. Psota M, Psenkova MB, Racekova N, et al. Cost-effectiveness analysis of IDegLira versus basal-bolus insulin for patients with type 2diabetes in the Slovak health system. Clinicoecon Outcomes Res. 2017;9: 749-762.

33. Kvapil M, Prázný M, Holik P, et al. Cost-effectiveness of IDegLira versus insulin intensification regimens for the treatment of adults with type 2 diabetes in the Czech Republic. Diabetes Ther. 2017;8:1331-1134.
ClinicoEconomics and Outcomes Research

\section{Publish your work in this journal}

ClinicoEconomics and Outcomes Research is an international, peerreviewed open-access journal focusing on health technology assessment, pharmacoeconomics and outcomes research in the areas of diagnosis, medical devices, and clinical, surgical and pharmacological intervention. The economic impact of health policy and health systems organization also constitute important areas of coverage. The manuscript management system is completely online and includes a very quick and fair peer-review system, which is all easy to use. Visit http://www.dovepress.com/testimonials.php to read real quotes from published authors. 